\title{
CORRIGENDUM
}

\section{DNA computing circuits using libraries of DNAzyme subunits}

Johann Elbaz, Oleg Lioubashevski, Fuan Wang, Françoise Remacle, Raphael D. Levine and Itamar Willner

Nature Nanotechnology 5, 417-422 (2010); published online: 30 May 2010; corrected after print: 9 February 2011.

In the version of this Letter originally published, components of the systems illustrated in Figs 3a-d, 4a and 4d were incorrectly labelled. In the Supplementary Information, components of the systems illustrated in Figs S7a, S9a-c and S10 were also incorrectly labelled. These errors have now been corrected in the HTML and PDF versions of the text, and in the Supplementary Information. 